\title{
Juggling work and family beyond the Mind-Set: Work-family conflict in Malaysian perspective
}

\author{
Gouri A. Domnic Jacob ${ }^{1,2, *}$, Karuthan Chinna ${ }^{3}$, Ali Boerhannoddin ${ }^{4}$, Rosila Bee Mohd Hussain ${ }^{5}$ \\ ${ }^{1}$ Institute of Graduate Studies, University of Malaya, Kuala Lumpur, Malaysia \\ ${ }^{2}$ Faculty of Business Administration, University of Technology MARA, Selangor, Malaysia \\ ${ }^{3}$ Faculty of Medicine, University of Malaya, Kuala Lumpur, Malaysia \\ ${ }^{4}$ Faculty of Economics and Administrative, University of Malaya, Kuala Lumpur, Malaysia \\ ${ }^{5}$ Faculty of Arts and Social Sciences, University of Malaya, Kuala Lumpur, Malaysia
}

\section{A R T I C LE INFO}

\section{Article history:}

Received 15 July 2016

Received in revised form

22 October 2016

Accepted 10 November 2016

\section{Keywords:}

Work-family conflict

Work-family balance

Spousal support

Gender ideology

Mother's mind-set

\begin{abstract}
A B S T R A C T
This article is to explore the dimensions of 'mind-set' among Malaysian dualearners in the work-family context. The primary goal of this study is to understand the effect of spousal support in overcoming work-family conflict and as a 'tool' to break those 'mind-sets'. In this study an In-Depth interview methodology was used. A total of 18 dual-earners were interviewed to understand the mind-set of the dual-earners. Based on these interviews, it is evident that Gender Role Ideology has taken root in our society. The main themes are derived from the interviews and these themes are the root of the ideology and mind-set among these groups of people. Two dimensions of mind-set have been identified. The first mind-set is the "gender stereotype mind-set" based on how men and women are supposed to be influenced by religion, culture, beliefs and norms. The second mind-set is described as the "mother's mind-set". In this type of mind set, mothers believe that they cannot let go the responsibility of child care and nurturing to the fathers because they are not confident of the fathers' capability in taking care the children. The results from this study highlight the importance of mind-sets that cause work-family conflict among Malaysians. The implications of this study were discussed. This study identifies the specific themes for workfamily conflict in the Malaysian Perspective. The study also focuses on mindsets that create work-family conflict in the Malaysian Perspective.
\end{abstract}

(C) 2017 The Authors. Published by IASE. This is an open access article under the CC BY-NC-ND license (http://creativecommons.org/licenses/by-nc-nd/4.0/).

\section{Introduction}

Work and family are the key domains of our life and it is becoming the major area for organizational researches (Parasuraman and Greenhaus, 2002). Clark (2000) and Voydanoff (2005) argued that work and family are the two most important domains' in people's life and as a results work and family can cause conflict if they compete with each other. There has been a dramatic increase in the amount of research that has proved the relationship between work and family. To explain the nature of the relationship between work and family roles, variety of linking mechanisms have been proposed (Edwards and Rothbard, 2000). Almost, every working individual experiences work life and family

\footnotetext{
* Corresponding Author.

Email Address: gouri296@salam.uitm.edu.my (G. A. D. Jacob) https://doi.org/10.21833/ijaas.2017.04.021

2313-626X/C 2017 The Authors. Published by IASE.

This is an open access article under the CC BY-NC-ND license

(http://creativecommons.org/licenses/by-nc-nd/4.0/)
}

life challenges daily (Karatepe, 2010; Netemeyer et al., 2005). Many working and married individuals all over the world are trying to juggle between work and family demands and responsibilities to strike a balance between work and family in their life. We often play different roles, such as an employee, a spouse, a mother, a father and etc. in our daily life; these roles should however be kept separate and function independently (Kanter, 1977).

Work-family conflict is an effect that occurs when the demands of work and family increase and the individual is faced with difficulty in managing this pressure. Work-family is defined as a type of interrole conflict in which responsibilities from the work and family domains are to some degree incompatible (Greenhaus and Beutell, 1985). Workfamily conflict is an important area because workfamily has been empirically related to negative work attitudes (Frone et al., 1992). This relationship has shown effects on family life such as, personal satisfaction, family satisfaction, family commitments, family involvement, and marital satisfaction, 
relationship with spouses, children, and parents (Bedeian et al., 1988; Frone et al., 1992;1997; Frone, 2000; Kelloway et al., 1999; Nemoto, 2008; Parasuraman and Simmers, 2001; Parasuraman et al., 1992). Similarly, it has also shown to affect work attitude such as; job satisfaction, work performance, commitment, job involvement, withdrawal cognition, tardiness, absenteeism, productivity, work effort, lateness and turnover (Bedeian et al., 1988; Bruck et al., 2002; Greenhaus et al., 2001; Hackett et al., 1989; Kelloway et al., 1999; Peluchette, 1993). Even in health and wellness, work-family has been found to bring about negative effects such as; stress depression, burnout, heart disease, psychological distress, anxiety disorders, mood disorders, and substance abuse disorders (Bianchi and Milkie, 2010; Burke and Greenglass, 1999; Frone, 2000; Schmitt et al., 1980; Wiley, 1987).

In the recent years, the family structure has changed dramatically as dual-parent family with one income has become less common. This trend is being replaced by dual earner families, where both husband and wife struggle to carry the financial burden due to an increased in economic need at home. Increase in expenses and the need for more cash, has created a situation where both partners are compelled to find alternate sources of income to meet their family financial necessities (Bardoel et al., 2008; Greenhaus and Beutell, 1985). Working parents often have difficulties in working out a balance between employment responsibilities and family and child care responsibilities (Galinsky and Johnson, 1998). Based on the effects of work-family conflict, researchers have identified two outcomes of the work-family conflict. They believe that workfamily imbalance can create conflicts between work to family (Work Interference Family-WIF) and family to work (Family Interference Work - FIW) (Parasuraman et al., 1992).

In Malaysia, the change in the demography of the labour force has the involvement of married women in employment. This has resulted in the growing number of dual earner couples (Aminah, 2005). The participation of women, including married women in the labour force has continued to increase year after year, in Malaysia. This growth is aided by fact that more women are pursuing higher education and they are employed as professionals in public and private organizations (Nasurdin and Hsia, 2008). However, Aminah (2005) argued that the motherhood mandate is family entrenched, and therefore, married working women are facing difficulty in managing the work-family interface. In addition, they experience high level of Family Interference to Work (Aminah, 1998a).

Work-family issues are getting the attention from the media, government bodies, private organizations, and NGOs in Malaysia. The need for a work-family balance has been highlighted by at the Women's Summit 2009 by Dato Sharizat Abdul Jalil, Minister of Women, Family and Community Development, on 19 August 2009 at Sime Darby Convention Centre in Kuala Lumpur. In the Malaysian case, literature provides evidence of a significant relationship between work-family conflict and job satisfaction (Aminah, 2005) and women experienced more work interference with family than family interference with work (Aminah, 1998b).

For dual earners, it is seen that maintaining job demand and family demand has become the main issue in their life. This is because, their family role and work role control the way of their life. It is hard for them to strike a balance and get satisfaction without the help or support from their partners. Here, support from the spouse and family has shown to reduce family distress and conflict (Frone et al., 1997). In a multicultural country like Malaysia, a discussion on spousal support is not as easy as one thinks. In the Malaysian society, mothers serve as the primary caregivers in the family and fathers are the main bread winners. Furthermore, Malaysians are still influenced by certain beliefs, norms and culture based on our religious background. Religion shapes and teaches us about family, gender and marriage. It also specifies how a man or a woman, husband or wife, mother or father should play his or her respective roles (Sherkat, 2000). Even though religion has an effect on work-family conflict, the magnitude is different in women and men as it can always interpret the relevance of family and work demand for their work-family strategies (Ammons and Edgell, 2007).

Workers in countries that are undergoing rapid economic and cultural transitions experienced greater work-family conflict when compared to countries that are going through less transition (Barnett and Hyde, 2001). Furthermore, workers in transitioning economies who are traditional gender role stereotypes, experienced more work-family conflict than those living in economically advanced countries with egalitarian gender role stereotype (Aycan, 2008). In a study conducted in Malaysia on women's economic participation in the non-formal sector and the household division of labour, it was found that women whose husbands had less traditional orientation towards gender roles were less burdened with household chores. In other studies it was found that women whose husbands held a more egalitarian orientation tend to experience less work family conflict (Aminah, 1999).

There are some significant differences in the work-family conflicts experienced by men and women. A number of studies suggest that the overall well-being of women is lower when comparing to men. The men in the research on work-family conflict indicated facing less conflict. However, this is not due to the characteristic of men or that they have better coping strategies. It is due to societal stereotypes that dictate who is responsible for the family (Hochschild, 1989). This is the kind of mindset that holds men back from getting involved in doing household chores.

In the Malaysian cultural context, mind-set can be explained as a set of beliefs in a person which affect the outcome of the entire endeavour. Wikipedia defines mind-set as a set of assumption, methods or 
notations held by one or more people. Mind-set creates a powerful incentive within these people to adopt or accept prior behaviour, choices or tools. This understanding of mind-set will help us explore the dimensions of 'mind-set' among dual earner in work and family issues based on the Malaysian perspective. In other countries, such as China (Yang, 2005) and Iran (Mortazavi, 2006), men are the 'bread winners' and their work is considered as sacrifices for the family. But today's economical demand increase dual earners and there are large number of single parent. Which this situation increase different work-family responsibilities and increase the challenges of juggling both and this situation break the traditional mind set " husband works, wife stays at home" (Boles et al., 2001; Powell and Greenhaus, 2006).

Spector et al. (2004) compared studies from 18 countries and came to the conclusion that people across the globe experience work- family conflict. The magnitude of conflict may be stronger for in certain population compared to others, based on the societal or cultural beliefs in the population. Other literature also linked work-family issues with cultural beliefs, values and norms (Eby et al., 2005; Yang et al., 2000).

\subsection{Theories and background of the study}

Gender Role Ideology (GRI) provides the foundation for qualitative interview study. GRI refers to an individual's attitudes and beliefs about the roles of men and women. Traditional GRI indicates that women should pay more attention to family related responsibilities and men should pay more attention to work related responsibilities (Gutek et al., 1991). In other words, GRI explained how a person is judged on the appropriateness of behaviour and the different characteristic of men and women in a society. GRI gives the conceptual understanding for the present study, which explores and examines how dual earner couples with children overcome work-family conflict with spousal support.

Role theory which was derived from an early work on organizational stress has largely influenced the understanding of work-family conflict (Kahn et al., 1964). Role theory explained that roles are based on expectations of what is considerate an appropriate behaviour in a given position ( $\mathrm{Neal}$ and Hammer, 2007). Role conflict can be defined as role tension that results from conflicting role pressure, and role theory stipulates that inter-role conflict, a form of role conflict occurs when an individual engages in multiple roles that are incompatible, such as work and family roles. Based on this theory, dualearners with work and family roles tend to be tied down by their daily responsibilities and this situation can lead to a role overload and conflict within roles.

The consequences of role facing conflict can be explained by spillover theory. The perspective on the process of work-family balance and work family conflict are the proponents of spillover theory
(Aldous, 1969). Spillover happens when working individuals carry their behaviour, emotions, knowledge and skills that are created at workplace to their family life and from the family to the working environment (Staines, 1998). This theory provides us a clear picture on how an individual's situation at home can affect work and how work can affect the home.

Understanding of these theories helped us to draw a background for this study on dual earners with children in the Malaysian work-family context. This understanding also helped us to explore the actual mind-set and challenges that faced by dual earners.

\section{Method}

The current study was explored with qualitative design based on the thematic analysis. The data were collected through semi-structured interviews which provided self-effacing way to gained information and this method allow respondent to express themselves and share their experiences freely. Which, this method also helped to explore the dimensions of 'mind-set' among Malaysian dual-earners in the work-family context. To achieve this objective, 16 respondents were interviewed. The participant was purposively selected based on dual-earners with children criteria.

\section{Validity and reliability}

In order to ensure reliability, an interview schedule that followed a structure was designed accordingly to create repeatability and consistency. Merriam (1998) mentioned identification of the researcher's biases may also add validity to qualitative research. In this study the author applied active listening techniques during interview sessions and explained the interview process to each respondent. Creswell and Miller (2000) defined validly as how precisely the information represents the realisms of the social phenomena to the respondents and how reliable is it to them. Based on this, to maintain the information flow from the interview process the author have followed strictly to the step by step analysis process as explained in data collection. The steps are included of member checking to validate interview transcription. The drafted transcripts were personally sent by the author to the respondent to review of what they have said and confirmed the information. The data was analysed by using Braun and Clark's thematic method. Finally peer review was used to support the interview finding. In this study, in-depth interview method was very vital because the author could see and feel the real situation that going through by the respondent. This happens when the respondents are expressing themselves and share their feelings with the author during interview session. As explained by Kvale (1996) 'in-depth focus makes it possible to investigate the detail relationship of a specific behaviour to its context, to work out the logic of the 
relationship between the individual and the situation".

\section{Participants}

Among the 16 married and working respondents, 7 were males and 9 were females and they were from different religious background, such as Muslims, Hindus, Buddhist and Christians. Purposive sampling was used in this method to ensure the participant could share the best knowledge and experiences in work-family conflict issues. The respondents were chosen from amongst those who were willing to share their experiences and thoughts on work-family issues through an interview. This is believed these participants are going through on juggling work and family in daily basis. The interviews were done individually and face to face. Each interview ranged from 25 minutes to 45 minutes, in a quiet setting of their office and some at their home. This said method also helped the researcher to understand the actual personal experiences of the participants in a culturally sensitive society (Sarantakos, 2005). This in-depth interview also allowed the researcher to seek further information about their opinions on certain issues. This interview type not only provided insights into a matter, it also initiated access to corroboratory or contrary sources of evidence (Yin, 2009). The interview was continued until data saturation was reached at 16 respondents. This means, the author stopped the interviews when the information was repeated and the answer for the study was achieved.

Open ended questions such as, "Do family issues or problems affect your work?", "Do work issues or problems affect your family?" were used to explore and understand work-family conflict among the respondents. Questions such as, "Are you getting help from your spouse to reduce your work-family conflict?", "Do you help your spouse in overcome work-family conflict?, "Do you think spousal support is important in reducing work-family conflict?" were used to understand the importance of spousal support among these respondents.

The experience and situation of work-family conflict that was shared by 16 respondents is summarized in Table 1. Evidence of work-family conflict and the need for spousal support to overcome work-family conflicts is presented in Table 1.

\section{Data analysis and finding of study}

The interviews were conducted by the first author. The interviews were audio recorded and transcribed verbatim after each session.

The transcript from the interviews was analysed using thematic analysis. Braun and Clarke (2006) had given six phases of thematic analysis, namely; familiarizing self with data, generating initial codes, searching for themes, receiving themes, defining and naming themes, and producing the report. The data collection process involved recording the interview sessions and later transcribing it. Thematic method is an analytic approach that leads to organizing and analysing the data through examining in deep details (Smith and Sparkes, 2009). Thematic analysis is used in this study to describe the key issues of workfamily conflict among dual earners in Malaysia.

Based on the interviews with 16 respondents, it seems that Gender Role Ideology has taken root in our society. The main themes were derived using the qualitative analysis as shown in Fig. 1. In this study, five themes have been identified in the Malaysian context and these themes are also influenced by two main mind sets as shown in Fig. 1.

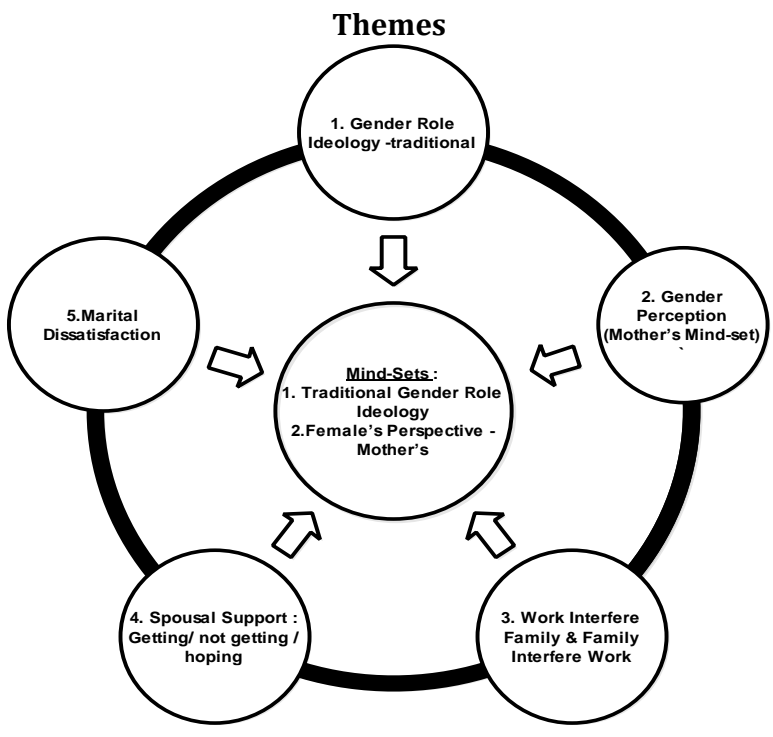

Fig. 1: Work-family issues in Malaysia

\subsection{Gender role ideology}

In this paper, the gender issue is considered neutral. This implies the traditional conviction held, that is, a woman's domain is the family and a man's domain is the sphere of paid work. However, this positioning itself does not change the reality of the gendered sphere in the cultural aspects of workfamily life as revealed by this research finding. Despite the growth in women's participation in paid work over the past half century, women still retain the close tie with family care and domestic responsibilities (Cornell, 1987). One respondent, a Sikh, relates how gender roles are still designated by their traditional beliefs and culture, as she recalled:

"Well, I am doing all the housework. My husband was brought up in very conservative family, where he believes that holding broom - brings bad luck for males in the house (His grandmother and mother thought him this). So I can't expect help from him when it comes to house hold chores."

Experience of the respondent, gives us clear picture on how culture influence work and family. Culture consists of patterned ways of thinking, feeling and reacting, acquired and transmitted mainly by symbols, constituting the distinctive achievements of human groups, including their embodiments in artefacts; the essential core of 
culture consists of traditional ideas and especially their attached values (Kluckhohn, 1951). The conceptualization of culture, places strong emphasis on values including what is important in one's life (work or care of the family), assumptions, beliefs and norms that distinguish one human group from another. They are also reflected by individual values, resources and opportunities. Even though time-use studies show that men have increased their efforts in balancing work-family life, including childcare, in the recent decades (Bianchi et al., 2000; Craig et al., 2010), they point out that women have also increased the average time spent on care in what constitutes as ideas of proper parenting. In this case, society as a whole allows a degree of flexibility in acting out each gender role. On the other hand, acceptable role limits are often in a state of flux and produces uncertainty about what appropriate gender role behaviour should be.

Table 1: Based from interview analysis: Themes were identified

\begin{tabular}{cl}
\hline No. & \multicolumn{1}{c}{ WORK-FAMILY CONFLICT } \\
\hline 1 & $\begin{array}{l}\text { "I'm too tired but I've no choice, I've to do } \\
\text { what I've to do at home after work" } \\
\text { At work, I'm always thinking about children. }\end{array}$ \\
& $\begin{array}{l}\text { Sometimes, have to stay longer at school for } \\
\text { certain activities that deprive my time with } \\
\text { the children. } \\
\text { After work, I rush to send the kids to school } \\
\text { and tuitions. }\end{array}$
\end{tabular}

3 Sometime at work, I think about family, I feel so stressed because I've so much to do at work and at home.

I don't really think about family while doing my duty.

4 My wife complains that I'm spending more time at work.

I always come home late, because of my work I don't see that as a problem.

5 I don't really spend much time with the kids during weekdays.

Sometimes I've to bring back my work. After dinner usually I'll sit with my lap top to

6 complete my office work for the day. My wife is actually not very happy about this. But I've no choice, my work is such.

Family doesn't affect my work.

7 Work is work, family is family.

Normally, when the children are not well or there are things at home that need to be

8 addressed urgently and being unable to take leave, will affect my concentration in a way.

Silly mistakes at work place which can be 9 avoided. Release my anger on husband and children.

Not facing this problem at the moment. I don't think about family at work and once I am back I don't talk or think about job.

Family does not interfere with my work unless certain problems arise such as a family members fall sick and etc.

11 Because of my work, I have to meet people after office hours. That might interfere with my family time.

When I am about to go back and the thought of what would be waiting at home comes to me.

12 At work I will try not to think about family and problems. Try to complete the job for the day.

13 Too much work to do at home, sometimes don't know where to start.
Not really getting help from spouse with housework. Only weekends such as some repairs or shopping.

Sometimes, I feel upset, I've to do everything at home. Kids and house hold chores make me tensed.

Not getting help from spouse because he is out- station most of the time.

I'm hoping so much to get help from spouse. My spouse only good at certain task such as watching the kids, so at end of the day I have to do all myself.

My wife does most of the housework with the help of children.

I usually help them during our long holidays or weekends.

My wife will do the daily chores at home.

She'll plan for the weekend so that we can spend some time together.

My spouse will handle housework and the kids.

When come to discipline issues and children than I will involve.

I am from very conservative family. Certain task is given for man and women. I am doing my job as bread winner and my wife does the housework and taking care the children.

I am doing the bulk of the work at home... however, my husband has been a great supporter... and thankfully he had been great getting the laundry done and helping out with the children as much as he can, which is a relieve. Otherwise, it would be truly difficult to continue working.

Myself and my hubby helps me most of the time, (e.g.:- take care the baby and helps with some cleaning at home during the weekend.

First year of marriage life, I couldn't cope. Everything is different then. I start to plan a new strategy to make it balance. Now everything is smooth with my husband besides me.

Imbalance occurs when you are not satisfied at home or work - dissatisfaction at home or work shows that you are facing an imbalance of work-family life).

So far I am not in this situation yet. My wife is taking care of things at home and updating me with things that I have to know and get involve. Life seems to be good so far.

Well, my wife is doing most of the housework.

My wife prefers to do things for the children such as feeding and preparing them. This is because she thinks; she can do better for them. "Mothers always better" - this makes me sit and watch her.

My spouse doesn't help in the housework because we have our maid.

I will be much happier if he can spend more time with the children because that really makes me occupied at home. I have no time for myself.

Well, I am doing all the housework. My husband was brought up in very conservative family, where he believes

- THEME
- Work interfere Family
- Family interfere Work
- Not getting spousal support
- Gender Role Ideology
- Work Interfere Family
- Family Interfere Work
- Not getting spousal support
- Stress
- Gender Role Ideology
- Family Interfere Work
- Hoping so much for Spousal
Support
- Gender Role Ideology
- Marital Dissatisfaction -
- Gomplains from spouse
- Getting spousal support
- Gender Role Ideology

Getting spousal support

Gender Role Ideology

- Getting spousal support

- Gender Role Ideology

- Marital Dissatisfaction

- Getting spousal support Gender Role Ideology

Rarely experiences Family Interfere Work

Getting Spousal Support

- Getting Spousal Support

- Managing good coping strategy with the help of spouse

- Getting Spousal Support

- Getting spousal support - Gender Perception (Mother's Mind-set)

Family Interfere Work

Not getting spousal support

marital dissatisfaction

Hoping for Spousal Support in children care

- Family Interfere Work Not getting Spousal Support 


\begin{tabular}{|c|c|c|c|}
\hline & $\begin{array}{l}\text { Can't be without thinking about family during } \\
\text { work hours. }\end{array}$ & $\begin{array}{l}\text { that holding broom - brings bad luck for males in the house } \\
\text { (His grandmother and mother thought him this). So I can't } \\
\text { expect help from him when it comes to house hold chores. }\end{array}$ & $\begin{array}{l}\text { - Gender Ideology - culture } \\
\text { influences }\end{array}$ \\
\hline 14 & $\begin{array}{l}\text { Usually, I will be too tired, and sometimes I } \\
\text { wish just to throw myself on the bed and rest. } \\
\text { But I can't do that because I have too many } \\
\text { things to do at home. } \\
\text { At work, I will be thinking about things } \\
\text { happening at home or sometimes will be } \\
\text { thinking about what to cook my children and } \\
\text { husband. }\end{array}$ & $\begin{array}{l}\text { Not getting much help from my spouse. He comes home late } \\
\text { after work. As a wife I have no choice but just do my } \\
\text { responsibilities and carry on for another day. }\end{array}$ & $\begin{array}{l}\text { - Work Interfere Family } \\
\text { - Family Interfere Work } \\
\text { - Not getting Spousal Support } \\
\text { - Gender Ideology }\end{array}$ \\
\hline 15. & $\begin{array}{l}\text { Once I am back, I just wish to be quiet. } \\
\text { I am too occupied at work and have no time to } \\
\text { think about family but if my son is not feeling } \\
\text { well that really affects me at work. }\end{array}$ & $\begin{array}{l}\text { Once back my husband and I don't really talk much because } \\
\text { we both are too tired. } \\
\text { I will be rushing to finish the housework and at the same } \\
\text { time have to take care my toddler son. } \\
\text { My husband usually brings back work and he is occupied so } \\
\text { only helps me to do some housework during weekends. }\end{array}$ & $\begin{array}{l}\text { - Work interfere Family } \\
\text { - Family Interfere work } \\
\text { - Not getting spousal support } \\
\text { - Gender ideology }\end{array}$ \\
\hline 16. & $\begin{array}{l}\text { I am too occupied at work. } \\
\text { At home, I do reply emails and answer phone } \\
\text { calls from my colleagues and boss regarding } \\
\text { my job. } \\
\text { But it is not a problem. }\end{array}$ & $\begin{array}{l}\text { My wife has her own perception when come to me and } \\
\text { children. She always thinks that I don't know how to take } \\
\text { care of my kids. (Actually she is not really confident about } \\
\text { me taking care of the kids"). }\end{array}$ & $\begin{array}{l}\text { - Work Interfere Family } \\
\text { - WIF not a problem because } \\
\text { getting spousal support } \\
\text { - Gender Perception (Mother's } \\
\text { Mind-set) }\end{array}$ \\
\hline
\end{tabular}

\subsection{Gender perception (Mother's Mind Set)}

In the Malaysian context, our society still expects that a mother should give top priority to the family as the primary caregiver. This implies that although most women hold jobs outside their homes, they should spend most of their time with their families. This situation creates thoughts in their minds that they are the best caregivers and sometimes they find it difficult to pass this duty to their spouses. Similarly, some mothers are unable to hand over their family responsibilities to their spouses because they believe they can handle the matter more efficiently. In addition, they may not have the confidence in their partners' ability to cope. Working mothers also firmly believe that they have to care for the family and so they not allow their spouses to share the household and childcare. Traditionally, domestic work and child care are linked with women (Bittman et al., 2003). This has rooted in most women, and working women feel guilty about not spending enough time with their children and not doing household work as wish to. This mind set and guilty feeling become barrier to let go their home responsible to their spouse. The idea of women roles as perceived by their spouses are highlighted by the two statements below:

1st man: "Well, my wife is doing most of the housework. My wife prefers to do things for the children such as feeding and preparing them. This is because she thinks; she can do better for them. "Mothers always better" - this makes me sit and watch her."

2nd Man "My wife has her own perception when come to me and our children. She always thinks that I don't know how to take care of my kids. (Actually she is not really confident about me taking care of the kids)".

These statements pointed out how mother's mind set plays an important part to create work-family balance. At the individual level, WFC seems to be felt more strongly by men or women, depending on the strength of transition in gender roles or strength of role expansion (Barnett and Hyde, 2001), if the women or the mothers are not willing to share their home responsible with their spouses, this going to make their life more difficult and stressful. The two statements above show that individuals holding traditional gender role stereotypes and experiencing role expansion would be more prone to suffer from WFC when compared to those holding egalitarian gender role stereotypes. The acknowledgement by the two men that women 'can do better' or 'mother always do better'; shows that the mutual give and take attitude that leads to joint conjugal roles with shared or interchangeable activities. In balancing gender roles, childcare responsibility is influenced by values of gender and family, household division of paid work, social norms, class, and policy frameworks. These factors have effects on one another (Craig and Mullan, 2011). However, this research finding goes a step further to show that in the context of the Malaysian society, cultural beliefs and traditional norms are still influential factors in achieving a balance in a work-family life. This shows how mother's mind-set influences them in workfamily issues in Malaysia.

\subsection{Work interfere family (WIF) and family interfere work (FIW)}

Work-family role system composed of male work role, female work role, male family role and female family role. Work-family conflict can appear in two aspects; Work Interference with Family (WIF) and Family Interference with Work (FIW) (Pleck, 1977). In this study, based on the interviews with the 16 respondents proved they are facing Work interfere Family and Family Interfere Work. All nine women facing FIW and four of them are facing both situations.

Female 1 (WIF and FIW): "I'm too tired but I've no choice, I've to do what I've to do at home after work". At work, I'm always thinking about children.

Female 2 (FIW): "Normally, when the children are not well or there are things at home that need to be addressed urgently and being unable to take leave, will affect my concentration in a way". 
Female 3 (WIF and FIW): "Usually, I will be too tired, and sometimes I wish just to throw myself on the bed and rest. But I can't do that because I have too many things to do at home. At work, I will be thinking about things happening at home or sometimes will be thinking about what to cook my children and husband".

Two out of six male respondents are facing WIF and the other four male respondents deny experiencing of WIF or FIW because they are getting spousal support to take care the home and children. As the respondents:

Male 1 (WIF - deny): "I don't really think about family while doing my duty. My wife complains that I'm spending more time at work".

Male 2 (WIF - deny): "I always come home late, because of my work. I don't see that as a problem. I don't really spend much time with the kids during weekdays".

Male 3 (WIF - sometimes): "Family does not interfere with my work unless certain problems arise such as a family members fall sick and etc. Because of my work, I have to meet people after office hours. That might interfere with my family time".

Gender role theory argued that women, who are more involved in the family, will experience greater conflict in trying to balance work and family responsibilities. According to Jost and Banaji (1994), women as primary supporters of traditional gender roles, they should justify the prevailing inequalities in the social system, which they feel powerless to change. Women who internalize the traditional gender roles feel guilty for not fulfilling their wifely and motherly duties. This theory supported our finding on WIF and FIW, where we identified women in Malaysia are trying to follow the rhythm of life as caregiver and an employee face greater conflict compared to their partner.

\subsection{Spousal support}

Spousal Support is an important factor in reducing conflict in work-family life (Kirrane and Buckley, 2004). Noor (1999) in her study of employed women in Malaysia found that those who had more control over their work requirements are those who received support from their spouses. In addition, those who were more religious tend to experience lesser work-family conflict. Spousal support is divided into two different types: emotional support and instrumental support. Emotional support is the mental support by being by the side of the spouse and providing full assistance in their career and child care. Further, listening to their problems, giving advice and full encouragement in whatever they are involved in is emotional support (Aryee and Luk, 1996). Instrumental support is when the spouse does more chores at home to lighten the burden of the partner. For example, the husband does the laundry, cooks dinner etc. similarly; the wife pays the bills for the husband, doing extra chores at home when husband has to work outstation or do extra hours.

\subsubsection{Getting spousal Support}

Dual Earners, who get support from their spouses are believed to have a better life style overall when compared to those who are not getting any support from their spouses:

Female 1:

"I am doing the bulk of the work at home... however, my husband has been a great supporter... and thankfully he had been great getting the laundry done and helping out with the children as much as he can, which is a relief. Otherwise, it would be truly difficult to continue working"

Social resource that an individual creates with the help of the spouses helps to prevent stress (Bernas and Major, 2000). They argued that women who have spouses who offered support are less likely to experience stress. As one of the respondent said:

Female 2: "Myself and my hubby helps me most of the time, (e.g.: - take care the baby and helps with some cleaning at home during the weekend. First year of marriage life, I couldn't cope. Everything is different then. I start to plan a new strategy to make it balance. Now everything is smooth with my husband besides $m e^{\prime \prime}$

Among dual-earner couples, women are shouldering more responsibilities in adapting to work and family demands (Hochschild, 1989). Further, literature shows that married women are more responsible for housework and child care than their husbands (Aycan and Eskin, 2005; Cornell, 1987; Pleck, 1977; Yang et al., 2000). By getting help from their partners, working mothers can concentrate in managing their work and are able to handle their work-family conflict better. A man, who is getting spousal support, works happily without Family interference in Work. As the respondent:

Male Respondent: "Imbalance occurs when you are not satisfied at home or work - dissatisfaction at home or work shows that you are facing an imbalance of work-family life). So far I am not in this situation yet. My wife is taking care of things at home and updating me with things that I have to know and get involve. Life seems to be good so far."

\subsubsection{Not getting spousal support}

It is also revealed in this investigation that among working men and women in Malaysia, cultural beliefs and practices influence family expectations and they shape one's perception of work-family balance issues. Female respondents who are not getting spousal support have shared what they felt:

Respondent 1: "Sometimes, I feel upset; I've to do everything at home. Kids and house hold chores make me tensed. Not getting help from spouse because he is out- station most of the time"

Respondent 2: "Not getting much help from my spouse. He comes home late after work. As a wife I have no choice but just do my responsibilities and carry on for another day". 
The above statements show that, wives who are not getting spousal support are going through stress and conflict. Based from this study, the essentiality and closeness of the family among the respondents involved in this study illustrate how cultural environment influences the balance in their workfamily life. Integration of spouse and spousal support (the help, advice and understanding) is then seen as a necessity in facing interference from family, in order to achieve a work-family balance. It has been suggested that the male partner emphasizes selfreliance, emotional stability, aggressiveness and objectivity (Schein, 1973). However, if a person is unable to comply with the expectations of spousal support, he or she is likely to comply with nonsupportive spouse, emotionally; understanding, listening, affection, advice, for welfare, and instrumentally; helps in household chores and childcare (Adams et al., 1996). Voydanoff (2007) suggested two possible forms of conflict that is work-to-family conflict and family-to- work conflict. Work-to-family conflict is associated with family absence, poor family role performance, and family dissatisfaction and distress. Meanwhile, family-towork conflict is related to absenteeism, tardiness, poor job performance, and job dissatisfaction (Voydanoff, 2004).

\subsubsection{Hoping to get spousal support}

Existing literature on the relationship between spouse-partner support has been positively related to a number of work related outcomes and marital adjustment (Bird and Bird, 1986; Roskies et al., 2003; Roskies and Lazarus, 1980).

Respondent 1: "My spouse doesn't help in the housework because we have our maid. I will be much happier if he can spend more time with the children because that really makes me occupied at home. I have no time for myself"

Respondent 2: "I'm hoping so much to get help from spouse. My spouse only good at certain task such as watching the kids, so at end of the day I have to do all by myself."

Based on the above statements it is evident that, these wives are desperately hoping for spousal support. Earlier we have discussed the types of spousal support; instrumental and emotional support. Emotional support refers to a sympathetic, loving and caring behaviour and Instrumental support is the assistance or facilitation in task accomplishment or providing assistance (Lee and Ling, 2001).

Spousal support during illness, emotional support when necessary, and advice are seen to minimize fatigue and irritation (Bernas and Major, 2000). Some women hope to share their burden of home chores with their spouse and reduce their stressful days. They also wish to have time for them, just to take a short break after a hectic day. For both women and men a shift role from worker to mother or wife and to father to husband is not an easy task to handle if there is no support from their spouses.
Our family system needs adjustment and adaptation to make sure that one partner is not overburdened by the roles he or she plays. Partners should get spousal support to overcome work-family conflict and create a balance in their life.

\subsection{Marital satisfaction}

Dual earners create two sources of family income for greater economy stability at home. This situation avoids placing a heavy responsibility on the husband as the sole provider for the family. It also helps wives to get the satisfaction of working outside the home (Bartley et al., 2007). For these couples, adapting to the dual worker lifestyle can create conflict. The statements below from the respondents show that they are experiencing marital dissatisfaction:

Respondent 1:"My wife complains that I'm spending more time at work"

Respondent 2:"Once back my husband and I don't really talk much because we both are too tired. I will be rushing to finish the housework and at the same time have to take care my toddler son"

Respondent 3: "Sometimes I've to bring back my work. After dinner usually I'll sit with my lap top to complete my office work for the day. My wife is actually not very happy about this. But I've no choice, my work is such"

Marital happiness is conceptualized as the degree of personal satisfaction on how the partner feels about his or her marriage (Cherlin, 1996). The literature on marital satisfaction found that the division of household tasks plays a part in marital satisfaction. It is all about how fairness is perceived in the division of household chores rather than the actual division of labour. This is apparently the key to the wife's contentment. Other researchers also found that a perceived unfair division of labour decreased the wives' marital quality and it becomes a major source of conflict (Frisco and Williams, 2003; Stevens et al., 2007).

Bartley et al. (2007) suggested the use of negotiation skills among the partners to overcome work-family conflict and create work-family balance. They believe that negotiation skills can help resolve their differences. The ability to resolve a conflict in a timely fashion is a mutually beneficial way. It also proven, that negotiation skill is essential for success in all areas of life including marriage (Bazerman, 1998). Negotiation includes the partner's effort to understand the situation and accommodate accordingly, and this obviously shows spousal support. The ability to negotiate during times of stress and conflict so that neither partner feels overburdened with the demands of home and family should be beneficial to maintain acceptable levels of marital happiness during stressful periods (Grote and Clark, 2001).

For dual-earners, the time that they spend at home is very precious and they should negotiate well with their partner to reduce conflict and create a happy marriage. As we know, dual earners are usually faces with a stressful situation and are likely 
to bring up difficult emotions that need to be processed. When an individual has the ability to negotiate an agreement with his or her partner, this can result in more commitment and happiness in their marriage. All in all, this study clearly explained two mind-sets found in our Malaysian society which controlled the work-family issue. The mind-sets are shown in Fig. 1.

\section{Limitation and future research}

The present study had several limitations that should be considered. The respondent in this study are not from the same type of job or not from the same job level. Different job and different job level might give different stage of work-family conflict. Earlier researchers had discussed the differences between high job level workers and low job level workers that lead to different degrees of work-family conflict (Brett and Stroh, 2003; Drago, 2007; Greenhaus and Beutell, 1985). Future research could attempt to repeat this study on job levels or job types among dual earners to gain better understanding on work-family conflict.

Second limitation in this study is focus on the method of this study. Interview method has it weaknesses such as it is difficult to directly compare the results of in-depth interview because each interviews are unique and the sample size is small which the results are most probably don't represent the population. This situation provides opportunity to create more rigorous study in future which researcher should involve multiple method of data collection.

\section{Conclusion}

Malaysians are from a multicultural background with strong beliefs, and norms according to their respective culture, and this situation had influenced the way of life and created the different kind of mind-sets among them. Furthermore, these mindsets have created a unique atmosphere in workfamily issues and provide a cultural framework that specifically delegates the different responsibilities "who should do what" in the family work domain. However, most dual earners still have their own mind-set on work-family related issues. There are certain groups of people who still think that women belong at home and should take care of the house. These are views handed down from their forefather's era.

We can see how deep this view has taken root in certain people's mind as noted from the comment made by an individual at the event entitled "Women in Technology" at Microsoft Tech SEA 2008 in Kuala Lumpur. This also goes to show that some Malaysian male workers are still in the state of transition from the old role ideologies.

The concept of femininity and masculinity here refers to the degree in which a person sees himself or herself as masculine or feminine given what it means to be a man or woman in the particular society (Burke et al., 1988; Mead, 1935) and argues that the differences in temperament between men and women are not a result of their biological differences, but rather their differences in socialization and cultural expectations held for each sex. Based on this study, one of the most influential cultural expectations is from an individual's religion.

When religious perspective is included, it provides crucial resources that may help to manage stress in the work and family domains. As with other role involvements, however, the potential benefits of adding the religious domain may be moderated by the extent of one's religious involvements which are perceived as positive or negative (Pargament, 1997). Apart from involvement in work and family roles, involvement in a religion is a potentially powerful source of psychosocial resources. This is true of religion for several reasons, which includes; (1) It is a way of thinking that helps many people understand personal limitations and encourage them to look beyond themselves for solutions and explanations; and (2) It provides a moral framework that shapes personal expectations of an ideal family and general life arrangements (Ammons and Edgell, 2007); and (3) It provides a formal mechanism for positive social network building and enhancement of rolespanning skills or resources.

With respect to the cultural changes in the Malaysian society, another aspect with considerable importance in achieving work-family balance is the mind-set. Two forms of mind-set were identified; mind-set related to one's culture and a mind-set of a woman (or mother) as the better caretaker.

The male respondent explained how women are seen traditionally as caretaker. Meanwhile the female respondent shows that although women desire to advance at work, their ambition often gives way to childcare responsibilities. Although gender roles are expanding and modern values are endorsed, Malaysians still practise and hold on to their traditional values on the importance of family in the society (Aycan and Eskin, 2005). Therefore, despite the changes in the workplace, the family is still the primary site where gender norms are reproduced (through cultural mind-set) in order to achieve a work-family balance.

Therefore, dual earners with children should plan proper coping strategies to break and overcome these mind-sets in order to have work-family balance. Similarly, both partners should understand their own roles and also those of their spouse's. This is to make sure that, when necessary, they can help cushion each other's roles to overcome work-family conflict.

In most cases, issue of work-family related to fixed mind set. In a fixed mind-set, risk and effort are two things that might reveal individual's inadequacies and it shows that they are not up to the task. People with fixed mind-set do not believe in effort. Fixed mind-set individual always trying to prove themselves and they are super sensitive about being wrong or making mistakes. In this society fixed mind-set set should replace with effort mind- 
set which the dual earners should plan and put some effort to improvise and create work-family balance. This situation only can happen by helping each other, regardless of gender and culture which have been blocking their minds.

\section{Acknowledgment}

I would like to thank Institute of Graduate Studies (University of Malaya) and Faculty of Business Administration (University Technology of MARA) for their supports. I also would like to express my appreciation to International Postgraduate Network (IPN Malaysia) to give me an opportunity to present in their conference and publish in journal.

Parts of this manuscript were presented at WASET 2012 Paris International Conference. (August 2012)

\section{References}

Adams GA, King LA, and King DW (1996). Relationships of job and family involvement, family social support, and work-family conflict with job and life satisfaction. Journal of Applied Psychology, 81(4): 411-420.

Aldous J (1969). Occupational characteristics and males' role performance in the family. Journal of Marriage and the Family, 31(4): 707-712.

Aminah A (1998a). Work-family role conflict and life-satisfaction of married working women. Journal of Asian Women Studies, 3: $57-63$.

Aminah A (1998b). Gender differences in the boundary permeability between work and family roles. Pertanika Journal of Social Sciences and Humanities, 6(1): 43-49.

Aminah A (1999). Gender role orientation of husbands and workfamily conflict of wives in dual-earner families. Pertanika Journal of Social Sciences and Humanities, 7(1): 1-9.

Aminah A (2005). The interface of work and family roles: A quest for balanced lives. UPM Inaugural Lecture Series, Universiti Putra Malaysia, Serdang, Malaysia.

Ammons SK and Edgell P (2007). Religious influences on workfamily trade-offs. Journal of Family Issues, 28(6): 794-826.

Aryee S and Luk V (1996). Work and nonwork influences on the career satisfaction of dual-earner couples. Journal of Vocational Behavior, 49(1): 38-52.

Aycan Z (2008). Cross-cultural approaches to work-family conflict. In: Lero D, Korabik K, and Whitehead DL (Eds.), Handbook of work-family integration: Research theories and best practices: 353-370. Elsevier, New Jersey, USA.

Aycan Z and Eskin M (2005). Relative contributions of childcare, spousal support, and organizational support in reducing work-family conflict for men and women: The case of Turkey. Sex Roles, 53(7-8): 453-471.

Bardoel EA, De Cieri H, and Santos C (2008). A review of worklife research in Australia and New Zealand. Asia Pacific Journal of Human Resources, 46(3): 316-333.

Barnett RC and Hyde JS (2001). Women, men, work, and family. American Psychologist, 56(10): 781-796.

Bartley SJ, Judge W, and Judge S (2007). Antecedents of marital happiness and career satisfaction: An empirical study of dualcareer managers. Journal of Business and Public Affairs, 1(1): 1-14.

Bazerman M (1998). Judgment in managerial decision making. $4^{\text {th }}$ Edition, Wiley, New York, USA.
Bedeian AG, Burke BG, and Moffett RG (1988). Outcomes of workfamily conflict among married male and female professionals. Journal of Management, 14(3): 475-491.

Bernas KH and Major DA (2000). Contributors to stress resistance. Psychology of Women Quarterly, 24(2): 170-178.

Bianchi SM and Milkie MA (2010). Work and family research in the first decade of the 21st century. Journal of Marriage and Family, 72(3): 705-725.

Bianchi SM, Milkie MA, Sayer LC, and Robinson JP (2000). Is anyone doing the housework? Trends in the gender division of household labor. Social Forces, 79(1): 191-228.

Bird GW and Bird GA (1986). Strategies for reducing role strain among dual career couples. International Journal of Sociology of the Family, 16(1): 83-94.

Bittman M, England P, Sayer L, Folbre N, and Matheson G (2003). When does gender trump money? Bargaining and time in household work1. American Journal of Sociology, 109(1): 186214.

Boles JS, Howard WG, and Donofrio HH (2001). An investigation into the inter-relationships of work-family conflict, familywork conflict and work satisfaction. Journal of Managerial Issues, 13(3): 376-390.

Braun V and Clarke V (2006). Using thematic analysis in psychology. Qualitative Research in Psychology, 3(2): 77-101.

Brett JM and Stroh LK (2003). Working 61 plus hours a week: why do managers do it?. Journal of Applied Psychology, 88(1): 67 78.

Bruck CS, Allen TD, and Spector PE (2002). The relation between work-family conflict and job satisfaction: A finer-grained analysis. Journal of Vocational Behavior, 60(3): 336-353.

Burke PJ, Stets JE, and Pirog-Good MA (1988). Gender identity, self-esteem, and physical and sexual abuse in dating relationships. Social Psychology Quarterly, 51(3):272-285.

Burke RJ and Greenglass ER (1999). Work-family conflict, spouse support, and nursing staff well-being during organizational restructuring. Journal of Occupational Health Psychology, 4(4): 327-336.

Cherlin AJ (1996). Public and private families: An introduction. McGraw-Hill, New York, USA.

Clark SC (2000). Work/family border theory: A new theory of work/family balance. Human Relations, 53(6): 747-770.

Cornell RW (1987). Gender and power. Polity Press, Cambridge, UK.

Craig L and Mullan K (2011). How mothers and fathers share childcare a cross-national time-use comparison. American Sociological Review, 76(6): 834-861.

Craig L, Mullan K, and Blaxland M (2010). Parenthood, policy and work-family time in Australia 1992-2006. Work, Employment and Society, 24(1): 27-45.

Creswell JW and Miller DL (2000). Determining validity in qualitative inquiry. Theory into Practice, 39(3): 124-131.

Drago RW (2007). Striking a balance: Work, family, life. Dollars and Sense, Boston, USA.

Eby LT, Casper WJ, Lockwood A, Bordeaux C, and Brinley A (2005). Work and family research in IO/OB: Content analysis and review of the literature (1980-2002). Journal of Vocational Behavior, 66(1): 124-197.

Edwards JR and Rothbard NP (2000). Mechanisms linking work and family: Clarifying the relationship between work and family constructs. Academy of Management Review, 25(1): 178-199.

Frisco ML and Williams K (2003). Perceived housework equity, marital happiness, and divorce in dual-earner households. Journal of Family Issues, 24(1): 51-73. 
Frone MR (2000). Work-family conflict and employee psychiatric disorders: The national comorbidity survey. Journal of Applied Psychology, 85(6): 888-895.

Frone MR, Russell M and Cooper ML (1992). Antecedents and outcomes of work-family conflict: testing a model of the workfamily interface. Journal of Applied Psychology, 77(1): 65-78.

Frone MR, Yardley JK and Markel KS (1997). Developing and testing an integrative model of the work-family interface. Journal of Vocational Behavior, 50(2): 145-167.

Galinsky E and Johnson AA (1998). The business case for addressing work-life issues. Families and Work Institute, New York, USA.

Greenhaus JH and Beutell NJ (1985). Sources of conflict between work and family roles. Academy of Management Review, 10(1): 76-88.

Greenhaus JH, Parasuraman S and Collins KM (2001). Career involvement and family involvement as moderators of relationships between work-family conflict and withdrawal from a profession. Journal of Occupational Health Psychology, 6(2): 91-100.

Grote NK and Clark MS (2001). Perceiving unfairness in the family: cause or consequence of marital distress? Journal of Personality and Social Psychology, 80(2): 281-293.

Gutek BA, Searle S, and Klepa L (1991). Rational versus gender role explanations for work-family conflict. Journal of Applied Psychology, 76(4): 560-568.

Hackett RD, Bycio P, and Guion RM (1989). Absenteeism among hospital nurses: An idiographic-longitudinal analysis. Academy of Management Journal, 32(2): 424-453.

Hochschild AR (1989). Second Shift. Avon Books, New York, USA.

Jost JT and Banaji MR (1994). The role of stereotyping in systemjustification and the production of false consciousness. British Journal of Social Psychology, 33(1): 1-27.

Kahn RL, Wolfe DM, Quinn RP, Snoek JD, and Rosenthal RA (1964). Organizational stress: Studies in role conflict and ambiguity. Wiley, New York, USA.

Kanter RM (1977). Work and family in the United States: A critical review and agenda for research and policy. Russell Sage Foundation, New York, USA.

Karatepe OM (2010). The effect of positive and negative workfamily interaction on exhaustion: does work social support make a difference?. International Journal of Contemporary Hospitality Management, 22(6): 836-856.

Kelloway EK, Gottlieb BH, and Barham L (1999). The source, nature, and direction of work and family conflict: A longitudinal investigation. Journal of Occupational Health Psychology, 4(4): 337-346.

Kirrane M and Buckley F (2004). The influence of support relationships on work-family conflict: Differentiating emotional from instrumental support. Equal Opportunities International, 23(1/2): 78-96.

Kluckhohn C (1951). The study of culture. In: Lerner HDLD. (Ed.), Stanford University Press, Stanford, California, USA.

Kvale S (1996). Interviews-An introduction to qualitative research interviewing. Sage Publication, Thousand Oaks, USA.

Lee SKJ and Ling SC (2001). Work-family conflict of women entrepreneurs in Singapore. Women in Management Review, 16(5): 204-221.

Mead M (1935). Sex and temperament in three primitive societies. Dell, New York, USA.

Merriam SB (1998). Qualitative research and case study applications in education. Jossey-Bass, San Francisco, USA

Mortazavi S (2006). The Iranian family in a context of cultural diversity. In: Georgas J, Berry FJR, Vijver VD, Kagitcibasi C, and Poortinga YH (Eds.), Families across cultures: A 30-nation psychological study: 378-385. Cambridge University Press, New York, USA

Nasurdin AM and Hsia KL (2008). The influence of support at work and home on work-family conflict: Does gender make a difference. Research and Practice in Human Resource Management, 16(1): 18-38.

Neal MB and Hammer LB (2007). Working couples caring for children and aging parents: Effects on work and well-being. Lawrence Erlbaum Associates Publishers, New Jersey, USA.

Nemoto K (2008). Postponed marriage exploring women's views of matrimony and work in Japan. Gender and Society, 22(2): 219-237.

Netemeyer RG, Maxham III JG, and Pullig C (2005). Conflicts in the work-family interface: Links to job stress, customer service employee performance, and customer purchase intent. Journal of Marketing, 69(2): 130-143.

Noor NM (1999). Roles and women's well-being: Some preliminary findings from Malaysia. Sex Roles, 41(3-4): 123145.

Parasuraman S and Greenhaus JH (2002). Toward reducing some critical gaps in work-family research. Human Resource Management Review, 12(3): 299-312.

Parasuraman S and Simmers CA (2001). Type of employment, work-family conflict and well-being: a comparative study. Journal of Organizational Behavior, 22(5): 551-568.

Parasuraman S, Greenhaus JH, and Granrose CS (1992). Role stressors, social support, and well-being among two-career couples. Journal of Organizational Behavior, 13(4): 339-356.

Pargament KI (1997). The psychology of religion and coping. The Guilford Press, New York, USA.

Peluchette JVE (1993). Subjective career success: The influence of individual difference, family, and organizational variables. Journal of Vocational Behavior, 43(2): 198-208.

Pleck JH (1977). The work-family role system. Social Problems, 24(4): 417-427.

Powell GN and Greenhaus JH (2006). Managing incidents of workfamily conflict: A decision-making perspective. Human Relations, 59(9): 1179-1212.

Roskies E and Lazarus RS (1980). Coping theory and the teaching of coping skills. In: Davidson PO and Davidson FM (Eds.) Behavioral medicine: Changing health and life style: 38-69. Brunner/Marzel, New York, USA

Roskies E, Apte M, and Subbakrishnan DK (2003). Coping theory and the teaching of coping skills. In: Davidson PO and Davidson FM (Eds.), Behavioral medicine: Changing health and life style. Brunner/Marzel New York, USA.

Sarantakos S (2005). Social Research. $3^{\text {rd }}$ Edition, Hampshire: Palgrave Macmillan, New York, USA.

Schein VE (1973). The relationship between sex role stereotypes and requisite management characteristics. Journal of Applied Psychology, 57(2): 95-100.

Schmitt N, Colligan MJ, and Fitzgerald M (1980). Unexplained physical symptoms in eight organizations: Individual and organizational analyses. Journal of Occupational Psychology, 53(4): 305-317.

Sherkat DE (2000). That they be keepers of the home": The effect of conservative religion on early and late transitions into housewifery. Review of Religious Research, 41(3): 344-358.

Smith B and Sparkes AC (2009). Narrative analysis and sport and exercise psychology: Understanding lives in diverse ways. Psychology of sport and exercise, 10(2): 279-288.

Spector PE, Cooper CL, Poelmans S, Allen TD, O'driscoll MICHAEL, Sanchez JI, and Lu L (2004). A cross-national comparative study of work-family stressors, working hours, and wellbeing: China and Latin America versus the Anglo world. Personnel Psychology, 57(1): 119-142. 
Staines GL (1980). Spillover versus compensation: A review of the literature on the relationship between work and nonwork. Human Relations, 33(2): 111-129.

Stevens DP, Minnotte KL, Mannon SE, and Kiger G (2007). Examining the "neglected side of the work-family interface" Antecedents of positive and negative family-to-work spillover. Journal of Family Issues, 28(2): 242-262.

Voydanoff $P$ (2004). The effects of work demands and resources on work-to-family conflict and facilitation. Journal of Marriage and Family, 66(2): 398-412.

Voydanoff P (2005). Work demands and work-to-family and family-to-work conflict direct and indirect relationships. Journal of Family Issues, 26(6): 707-726.

Voydanoff P (2007). Work, Family, and Community: Exploring Interconnections. Journal of Marriage and Family, 69(3): 894896.
Wiley DL (1987). The relationship between work/nonwork role conflict and job-related outcomes: Some unanticipated findings. Journal of Management, 13(3): 467-472.

Yang $N$ (2005). Individualism-collectivism and work-family interfaces: A Sino-U.S. comparison. In: Poelmans S (Ed.), Work and family an international research perspective: 287-318. Erlbaum, Mahwah, USA.

Yang N, Chen CC, Choi J, and Zou Y (2000). Sources of work-family conflict: a Sino-US comparison of the effects of work and family demands. Academy of Management Journal, 43(1): 113-123.

Yin RK (2009). Case study research: Design and methods $4^{\text {th }}$ Edition. In United States: Library of Congress Cataloguing-inPublication Data, Thousand Oaks, USA. 